\section{Abstractions}

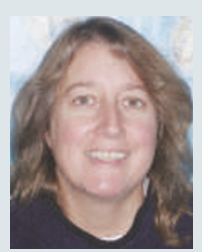

\section{FIRST AUTHOR}

Earth's ocean crust covers most of the planet's surface. But geophysicists don't have efficient or effective methods by which to understand its formation. As a graduate student at Woods Hole Oceanographic Institution in Massachusetts, Gail Christeson participated in one of the first attempts to drill through the oceanic crust and map the geological boundaries between the distinct layers of lavas and dykes that overlie volcanic rocks known as gabbros. Unfortunately, drilling beyond 100 metres proved too difficult. But many continued to question the long-held assumption that seismic maps, which use 'vibrations' to generate a broadscale picture of the underlying structure, correlate with the crust geology. Now a research seismologist at the University of Texas Institute for Geophysics in Austin, Christeson and her colleagues decided to bypass drilling and directly compare the geological and seismic features of two crusts ripped open by natural phenomena. On page 418, she and her team show that seismic data cannot be used to reliably map the geological boundary between lavas and dykes in young oceanic crust.

\section{How does oceanic crust formation affect} other Earth processes?

More than two-thirds of Earth's surface is covered by crust formed through the midocean ridge system. Anything we can do to understand how this formed will help us to work out how much heat is released during the process, which may affect the biological communities close to the vents. In addition, understanding how sea water circulates through these geological structures could explain how heat is transported from the crust to the sea floor. We speculate that there is a zone of some sort in which minerals can precipitate out of the sea water as a result of increased temperature and decreased porosity, possibly creating giant ore deposits.

How do your findings refute past beliefs? Our work shows that although their seismic structure is similar, two types of spreading ridge - fast and intermediate - look different geologically. So we can't reliably use the seismic method to map the geological boundary between lavas and dykes.

\section{What is the next step?}

The key question now is what the seismic differences that we've mapped are. The next step is to determine exactly what the upper 400-600-km layer of ocean crust does correspond to, now that we know it's not always the top of dykes. Then we'll be able to interpret all the data we've acquired. We plan to drill a hole through such a layer in young oceanic crust.

\section{MAKING THE PAPER}

\section{Logan Grosenick}

\section{Behavioural research finds that fish know their place.}

During a lab meeting about two years ago, Logan Grosenick presented research describing how fish determine the pecking order within their group - a process that depends not only on the physical attributes of individuals but also on their social interactions. The presentation inspired a lengthy discussion between Grosenick and Tricia Clement, another member of his lab at Stanford University in California. The two, along with their supervisor Russell Fernald, devised an experiment to test whether fish can figure out the social rank of other fish simply by watching how they interact. "We sat in front of a whiteboard and sketched the essentials of the project right then and there," recalls Grosenick.

The experiment used a large, square tank partitioned into several compartments and the extremely territorial native African fish Astatotilapia burtoni (see page 429). The central unit of the tank contained the designated 'bystander' fish, whose role was to observe. Five surrounding units each contained size-matched male fish - fish A to E - designated as 'rivals'. The researchers could lift an opaque barrier between any two compartments, so that the fish, while still physically separated, could see one another

With the opaque barriers down, Grosenick moved a fish from one unit into another fish's unit. Because the fish are so territorial, the resident fish in the unit, fish A, would attack the intruder, fish B. Grosenick then removed the barrier, making it possible for the bystander fish to watch the fight. The resident fish was always victorious. After seven minutes, the barrier would be replaced, and Grosenick would remove the defeated fish, returning him to his unit, and then stage a second fight.

This 'training' went on for 11 days, with

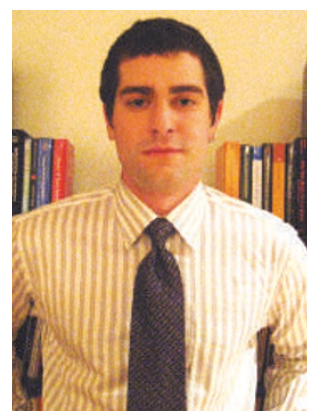

the bystander fish always seeing fish A defeat fish B, B defeat $C, C$ defeat $D$ and $\mathrm{D}$ defeat $\mathrm{E}$. "We were able to create an artificial dominance hierarchy for the bystander fish," says Grosenick. The observations were time-consuming

and demanded a lot of patience. "If anything startled the fish I would have to wait half an hour to let things settle down and then start again," adds Grosenick.

At the end of the training period, the researchers tested whether the bystander fish could infer from what he had witnessed that $B$ was dominant over $\mathrm{D}$, even though the two had never actually fought one another. To do so, Grosenick lifted the opaque dividers between $\mathrm{B}, \mathrm{D}$ and the bystander. He then timed how long the bystander spent in the vicinity of $B$ compared with $\mathrm{D}$. In most cases, the bystander spent more time near the 'weaker' fish, indicating that he knew to keep his distance from the dominant one. "We had expected a difference, but the magnitude of the difference was surprising," says Grosenick. The researchers were also surprised that the fish could recognize each other on the basis of appearance alone, because they are not very distinctive-looking.

The ability to make this sort of logical connection is known as transitive inference, and is described as a developmental milestone in children by renowned psychologist Jean Piaget. Transitive inference had previously been demonstrated in primates, rats and birds, but never in fish. "There has been a long debate about whether fish can reason in this way," says Grosenick, who is completing a master's in statistics. "This is compelling evidence that they can." He plans to extend the results using a more 'natural' environment. "I have been talking to an electrical engineer about tagging fish so that we can follow their behaviour while they move around a tank unconstrained," he says.

\title{
KEY COLLABORATORS
}

The findings of a group of

Australian palaeontologists suggest that climate change was not to blame for the extinction of the Australian Pleistocene megafauna. In 2002, John Long of the Western Australian Museum in Perth organized a series of expeditions to three caverns in the Nullarbor Plain of south-central Australia, where numerous fossils had been found. His team included specialists in Pleistocene cave sites, megafauna, small vertebrate fauna, microfossils and isotope geochemistry.

The authors identified one gastropod and 69 vertebrate species, including eight previously undocumented kangaroo species. After four years of evaluating their findings, they realized that new species were only part of the discovery. They had assumed that the Nullarbor Plain must have been substantially wetter than it is today in order to explain the diversity and number of the megafauna. But their evidence suggested that the environment was just as arid 400,000 to 800,000 years ago (see page 422) The researchers note that in the 500,000 years before their extinction the megafauna of southeastern Australia were resilient to climate change. The team speculates that, rather than climate change, increased bushfires, possibly lit by humans, spurred their demise. 